\title{
The Hyaluronan-Binding Serine Protease from Human Plasma Cleaves HMW and LMW Kininogen and Releases Bradykinin
}

\author{
Michael Etscheid ${ }^{1, *}$, Nicole Beer ${ }^{1}$, Edwin Fink², \\ Rainer Seitz ${ }^{1}$ and Johannes Dodt ${ }^{1}$ \\ ${ }^{1}$ Department of Hematology and Transfusion Medicine, \\ Paul-Ehrlich-Institute, Federal Agency for Sera and \\ Vaccines, D-63225 Langen, Germany \\ ${ }^{2}$ Department of Clinical Chemistry and Clinical \\ Biochemistry, University Hospital of Surgery, \\ Ludwig-Maximilians-University, 80336 Munich, \\ Germany
}

${ }^{*}$ Corresponding author

The influence of the hyaluronan-binding protease (PHBSP), a plasma enzyme with FVII- and pro-urokinase-activating potency, on components of the contact phase (kallikrein/kinin) system was investigated. No activation or cleavage of the proenzymes involved in the contact phase system was observed. The procofactor high molecular weight kininogen (HK), however, was cleaved in vitro by PHBSP in the absence of any charged surface, releasing the activated cofactor and the vasoactive nonapeptide bradykinin. Glycosoaminoglycans strongly enhanced the reaction. The cleavage was comparable to that of plasma kallikrein, but clearly different from that of coagulation factor FXla. Upon extended incubation with PHBSP, the light chain was further processed, partially removing about 60 amino acid residues from the $\mathrm{N}$-terminus of domain D5 of the light chain. These cleavage site(s) were distinct from plasma kallikrein or FXla cleavage sites. PHBSP and, more interestingly, also plasma kallikrein could cleave low molecular weight kininogen in vitro, indicating that domains $\mathrm{D5}_{\mathrm{H}}$ and $\mathrm{D} 6_{\mathrm{H}}$ are no prerequisite for kininogen cleavage. PHBSP was also able to release bradykinin from $\mathrm{HK}$ in plasma where the procofactor circulates predominantly in complex with plasma kallikrein or FXI. In conclusion, PHBSP represents a novel kininogen-cleaving and bradykinin-releasing enzyme in plasma that shares significant catalytic similarities with plasma kallikrein. Since they are structurally unrelated in their heavy chains (propeptide), their similar in vivo catalytic activities might be directed at distinct sites where PHBSP could induce processes that are related to the kallikrein/ kinin system.

Key words: Contact phase system /

Glycosoaminoglycans/Kinin/Kininogenase/PHBSP /

Plasma kallikrein/kinin system.

\section{Introduction}

A 'thrombin-like' activity, first identified by chromogenic assays in some prothrombin complex concentrates, may be associated with a 65-70 kDa protein of unusual chromatographic behaviour (Hunfeld et al., 1999). This enzyme was termed plasma hyaluronan binding serine protease (PHBSP) because it represented the functional enzyme of a truncated, catalytically inactive plasma hyaluronan-binding protein (Choi-Miura et al., 1996). A serine protease identical to PHBSP has recently been reported to activate plasminogen activators (Römisch et al., 2000) and FVII in a tissue factor-independent way (Römisch et al., 1999). Furthermore, in vitro-data showed that FV and FVIII are inactivated by this protease (Römisch et al., 1999, and our own unpublished observation). Therefore, a pro- and anticoagulatory, as well as a profibrinolytic potency is attributed to PHBSP. For all these functions, however, a physiological relevance remains to be shown.

PHBSP is a trypsin-like protease consisting of 537 amino acids in its mature proenzyme form (Choi-Miura et al., 1996). In the N-terminal part (propeptide or 'activation segment'; Khan and James, 1998) three epidermal growth factor-like and one kringle domain are present, in the C-terminal part the catalytic triade is found. A total concentration of $12 \mu \mathrm{g} / \mathrm{ml}$ (200 nM) PHBSP in plasma was determined by quantitative ELISA (Römisch et al., 2001). The proenzyme undergoes an intermolecular autocatalytic activation by cleavage at an internal $\mathrm{Arg}_{290}$-lle bond (Etscheid et al., 2000) resulting in an $\mathrm{N}$-terminal $48 \mathrm{kDa}$ heavy chain and a C-terminal $30 \mathrm{kDa}$ light chain held together by a single disulfide bond. PHBSP activity and proenzyme activation in vitro are effectively inhibited by plasma serpins, especially $\alpha_{2}$-antiplasmin and C1-esterase inhibitor.

The single-chain plasminogen activator-activating potency and the strong inhibition of PHBSP by C1-esterase inhibitor (Hunfeld et al., 1999; Römisch et al. , 2000) indicated catalytic similarities between PHBSP and the contact phase enzyme plasma kallikrein (PK). Very little is known about the interaction of PHBSP with components of the contact activation system (plasma kallikrein/kinin system). This system participates in important physiological processes like the surface-dependent, intrinsic pathway of blood coagulation, in fibrinolysis, in angiogenesis and in processes like inflammation or blood pressure regulation (Colman and Schmaier, 1997; Schmaier, 2000; Colman, 2001). The major components of the kallikrein/ kinin system are high molecular weight kininogen (HK, Williams-Fitzgerald-Flaujeac factor), plasma prekallikrein 
(PPK, Fletcher factor) and the coagulation factor XII (FXII, Hageman factor). Within the intrinsic coagulation cascade, the coagulation factor $\mathrm{XI}(\mathrm{FXI})$ is closely associated with the contact activation system (Donaldson et al., 1976; Cochrane and Griffin, 1979; Kaplan, 1979). C1 esterase inhibitor is considered as the major regulator of the surface-mediated contact phase system (Cameron et al., 1989; Colman, 2001).

$\mathrm{HK}$ is a single chain glycoprotein of $120 \mathrm{kDa}$, composed of 626 amino acids, comprising the domains D1$\mathrm{D} 4, \mathrm{D} 5_{\mathrm{H}}$ and $\mathrm{D} 6_{\mathrm{H}}$. In plasma $\mathrm{HK}$ is mostly found in complex with PK or FXI, mediated by domain D6 (Mandle et al., 1976; Thompson et al., 1977). The activated forms of both zymogens, plasma kallikrein (PK) and FXla, can cleave the pro-cofactor $\mathrm{HK}$ to finally release the vasoactive peptide bradykinin (BK), although the cleavage patterns differ (Scott et al., 1985; Mauron et al., 2000). Unlike FXla, BK release by plasma kallikrein leaves behind activated kininogen $(\mathrm{HKa})$ which has anti-adhesive and antiangiogenic functions (Colman, 2001). Low molecular weight kininogen (LK) is a $66 \mathrm{kDa}$ single chain glycoprotein representing a splicing variant transcribed from the same single-copy gene as HK, yielding identical domains D1 to D4. The procoagulatory PK- and FXI-binding domain $\mathrm{DG}_{\mathrm{H}}$ is missing in $\mathrm{LK}$, and domain $\mathrm{D} 5_{\mathrm{L}}$ is only $4 \mathrm{kDa}$ in length and its amino acid sequence is unrelated to $D 5_{H}$ of HK (Takagaki et al., 1985). FXI and PPK are structurally related proteins sharing $58 \%$ amino acid sequence identity (De La Cadena et al., 1994). The binding regions for HK have been mapped to apple domains A1, A2, and A4 of PK (Page et al., 1994; Renné et al., 1999) and A1, A2, and A4 of FXI (Baglia et al., 1990; Renné et al., 2002), respectively. $\mathrm{PK}$ consists of an $\mathrm{N}$-terminal heavy chain of $52 \mathrm{kDa}$ that is disulfide-linked to two light chain variants (36 or $33 \mathrm{kDa}$ ). This $\mathrm{PK}$, designated $\alpha$-kallikrein $(\mathrm{PK} \alpha)$, can catalyze an autolytic cleavage within the second apple domain generating $\beta$-kallikrein $(\mathrm{PK} \beta)$, which has a similar FXII-activating potency but a diminished rate of cleavage of HK (Colman et al., 1985).

Here we demonstrate that the hyaluronan-binding serine protease from human plasma represents a novel kininogen-cleaving enzyme, and we show that also in plasma the vasoactive nonapeptide bradykinin is released from kininogen. The cleavage mechanism is compared to that of other kininogen processing plasma enzymes. We further investigated whether besides high molecular weight also low molecular weight kininogen could function as a substrate for PHBSP and whether glycosoaminoglycans (GAGs) affect kininogen cleavage by PHBSP. The physiological relevance of the findings is discussed.

\section{Results}

\section{Proenzymes of the Contact Activation System}

In order to evaluate the influence of PHBSP on the contact activation system the purified proenzymes of this system were incubated with PHBSP. When commercially available preparations of PPK, FXI and FXII (each at a final concentration of $2.8 \mu \mathrm{M}$ ) were treated with $78 \mathrm{~nm}$ PHBSP no cleavage products could be observed by SDS-PAGE (Figure 1A). Also at equimolar ratio no cleavage was detectable (not shown) indicating that none of these proenzymes is a substrate of PHBSP. From these results it was concluded that PHBSP does not directly participate in the regulation of the enzymes of the contact

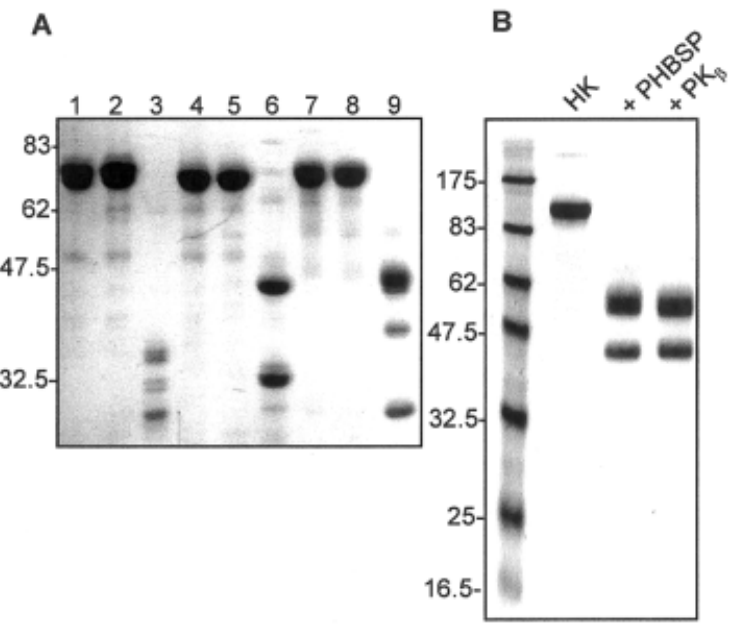

Fig. 1 Effect of PHBSP on Components of the Kallikrein/kinin System.

(A) Plasma prekallikrein (PPK) and the coagulation factors FXI and FXII were incubated with PHBSP for $90 \mathrm{~min}$ at a substrate to enzyme ratio of 35:1. Samples were subjected to SDS-PAGE under reducing conditions and the gel was stained with coomassie brilliant blue. PPK (lane 1 and 2), FXI (lane 4 and 5) and FXII (lane 7 and 8) are shown each before and after treatment with PHBSP. As controls, plasma kallikrein (PK, lane 3), FXla (lane 6), and FXIla (lane 9) are shown. The results are representative of at least two independent experiments. (B) Gel analysis of HMW kininogen treated with PHBSP or plasma kallikrein. The fragment sizes of the pre-stained molecular weight marker (New England Biolabs, Leusden, The Netherlands) are indicated. This gel is representative of at least three independent experiments.

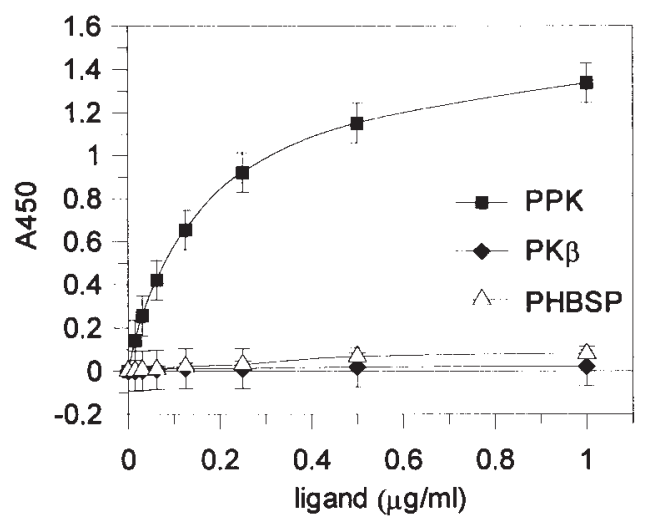

Fig. 2 Ligand Binding Assay.

The concentration-dependent binding of PPK, PK $\beta$ and PHBSP to immobilized HMW kininogen was studied in an ELISA assay. Each data point represents the mean of four measurements \pm SD. 
activation system. Lanes 3, 6, and 9 show PK, FXla and FXIla for comparison. The lack of a visible heavy chain of $52 \mathrm{kDa}$ in the commercial PK preparation (lane 3) indicated that it is apparently not the $\alpha$-form but mostly the $\beta$ form, presumably as result of autolproteolytic cleavage during preparation or storage. A strongly reduced HKbinding potency of the $\mathrm{PK}_{\beta}$ used in this study compared to an equal amount of PPK was found in a ligand-binding assay (Figure 2). In the same assay PHBSP exhibited only a very weak affinity for HK. Thus, the lack of both enzymes to bind to HK allowed to compare only their catalytic activities, independent of the strong complex formation between $\mathrm{PK}_{\alpha}$ and $\mathrm{HK}$.

\section{Cleavage of HMW Kininogen in Solution}

When the procofactor HMW kininogen (HK) was incubated with PHBSP under identical conditions as described for the zymogens of the kallikein/kinin system, the reduction of the $120 \mathrm{kDa}$ procofactor band and the generation of two bands of approximately 62 and $47 \mathrm{kDa}$ was observed, generating a cleavage pattern indistinguishable from that obtained with plasma kallikrein (Figure 1C). From here we started a more detailed study of the HKcleaving property of PHBSP in comparison to the welldescribed HK-processing enzymes, PK and the coagulation factors FXla and FXIla.
In a time course the cleavage of purified procofactor HK by these enzymes in the absence of a surface reactant was analyzed side-by-side. The reaction products were subjected to reducing SDS-PAGE and Western blot analysis with a HK-specific polyclonal antibody. The incubation of HK with PK $\beta$ or PHBSP (Figure $3 \mathrm{~A}, \mathrm{C}$ ) resulted in the disappearance of the $120 \mathrm{kDa}$ procofactor band and in the generation of a $\sim 62 \mathrm{kDa}$ band doublet, presumably the heavy chain and a slightly faster migrating intermediate of the light chain. Both enzymes further processed the intermediate, concomitant with the appearance of a $\sim 47 \mathrm{kDa}$ band, the expected mature light chain of activated HK (HKa). The PHBSP-mediated cleavage products, including the intermediate, were similar in size to the products generated by cleavage of $\mathrm{HK}$ with plasma kallikrein.

PHBSP (and PK $\beta$ ) showed a different cleavage pattern compared to FXla. The treatment of HK with FXla showed the generation of a $\sim 62 \mathrm{kDa}$ heavy chain. The intermediate of the light chain was not visible (Figure 3B). The incubation of $\mathrm{HK}$ with FXla for more than $1 \mathrm{~h}$ resulted in the disappearance of the mature light chain, presumably by further cleavage at $\mathrm{LyS}_{502}-\mathrm{Thr}_{503}$ removing both surface binding regions from the light chain as reported earlier (Scott et al., 1985; Mauron et al., 2000). This cleavage step was not observed with PHBSP or PK $\beta$. From the data presented above it was concluded that PHBSP
A

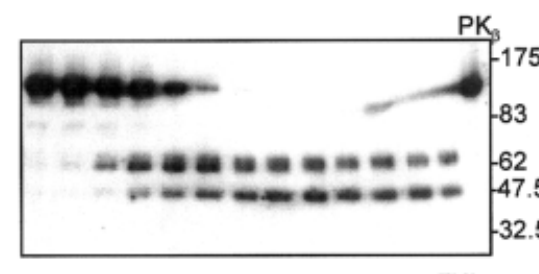

B

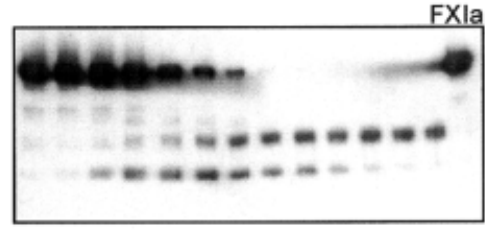

C

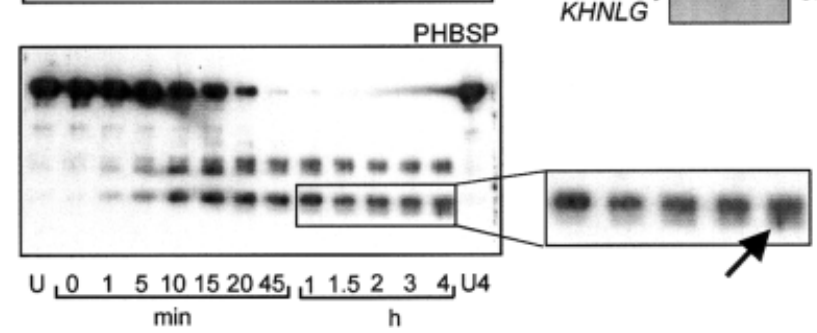

D

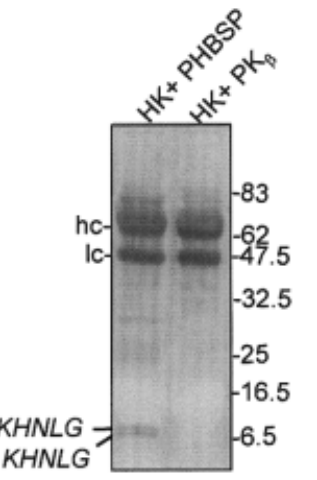

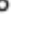

.

Fig. 3 Western Blot Analysis of HK Cleavage.

The rates of HK processing by (A) plasma kallikrein, (B) FXla and (C) PHBSP are shown. One hundred ng of HK, treated as indicated, was loaded on a Laemmli gel under reducing conditions and was transferred to a PVDF membrane. The products were immunodetected with an anti-HK antibody and were visualized using a chemiluminescent substrate. The incubation time is indicated below the bottom gel. Untreated HK (U) and HK treated for $4 \mathrm{~h}$ in buffer (U4) are also shown. The further processing of the HK light chain by PHBSP is enlarged for better visibility. (D) Additional PHBSP-specific cleavage products. HK (15 $\mu$ g), treated either with PHBSP or PK $\beta$, were separated by SDS-PAGE and the gel was Coomassie Brilliant Blue-stained. The results shown in panels A, C, and D are representative of at least three independent experiments, the experiment shown in panel B was repeated once with the same result. The positions of the heavy chain (hc) and the light chain (Ic) of HKa are indicated. The N-terminal sequences of two 7 kDa bands, generated by PHBSP, are shown on the left. 
cleaves HK in a similar way as PK but clearly different from FXla.

FXIla, structurally related to PHBSP, has been reported to cleave HK in prekallikrein-deficient plasma in the presence, but not in the absence of kaolin to yield cleavage products very similar to those generated by PK (Wiggins, 1983). Our studies revealed that in the absence of kaolin FXIla did not cleave HK (data not shown). In contrast, cleavage of HK by PHBSP was not dependent on activating surfaces and was therefore clearly different to the activation of HK by FXIla.

\section{Cleavage Sites on HK}

Amino-terminal sequencing by Edman degradation of the $47 \mathrm{kDa}$ light chain generated by PHBSP yielded the sequence KHNLGH, demonstrating that PHBSP cleaved the intermediate at the same $\operatorname{Arg}_{419}$-Lys 420 bond as PK. Similar to PK, PHBSP removed a 47 amino acid residue polypeptide $\left(\mathrm{Ser}_{372}-\mathrm{Arg}_{419}\right.$ ) from the intermediate $62 \mathrm{kDa}$ fragment to release the mature light chain $\left(\mathrm{Lys}_{420}-\mathrm{Ser}_{626}\right)$.

\section{Additional Cleavage of the Light Chain of HK}

During incubation of HK for several hours with PHBSP the mobility of the light chain increased, best seen in the sample after $4 \mathrm{~h}$ incubation (compare Figure $3 \mathrm{~A}$ and $\mathrm{C}$, blow-up). In order to identify additional cleavage site(s), $15 \mu \mathrm{g} \mathrm{HK}$ were treated for $4 \mathrm{~h}$ with PHBSP or PK and was subsequently separated on a 10-20\% SDS-PAGE for low molecular weight proteins. Repeatedly two fragments of approximately $7 \mathrm{kDa}$ became visible (Figure 3D) which were not present upon $4 \mathrm{~h}$ treatment of $\mathrm{HK}$ with PK $\beta$. Partial amino acid sequence analysis revealed that the N-termini of both $7 \mathrm{kDa}$ fragments, KHNLG, were identical, representing the $\mathrm{N}$-terminus of the mature light chain of HK. The location of the additional PHBSP-cleavage site(s) have still to be determined. A size of $7 \mathrm{kDa}$ would correspond to approx. 60 amino acid residue peptides, hence reaching from Lys $_{420}$ to a lysine- and histidine-rich domain at $\mathrm{Lys}_{480}$ within the second surface binding region of the $\mathrm{D} 5_{\mathrm{H}}$ domain (De La Cadena et al., 1994).

\section{Release of Kinin}

In a radioimmunoassay with bradykinin-specific antibodies the completeness and the rate of the kinin release by PHBSP and PK $\beta$ was compared. Additionally, in this experiment it was investigated whether low molecular weight kininogen (LK) can function as substrate for PHB$\mathrm{SP}$ or plasma kallikrein. From master incubation mixtures of HK or LK with PHBSP or PK $\beta$ aliquots were withdrawn at specific time points, ethanol-precipitated to remove the high molecular weight proteins, and the concentration of free kinin in the vacuum-dried ethanol supernatant was determined (Figure 4). In each aliquot withdrawn from the reaction mixture $27 \mathrm{pmol}$ kininogen were present. The cleavage of HK by PHBSP released $\sim 20$ pmol

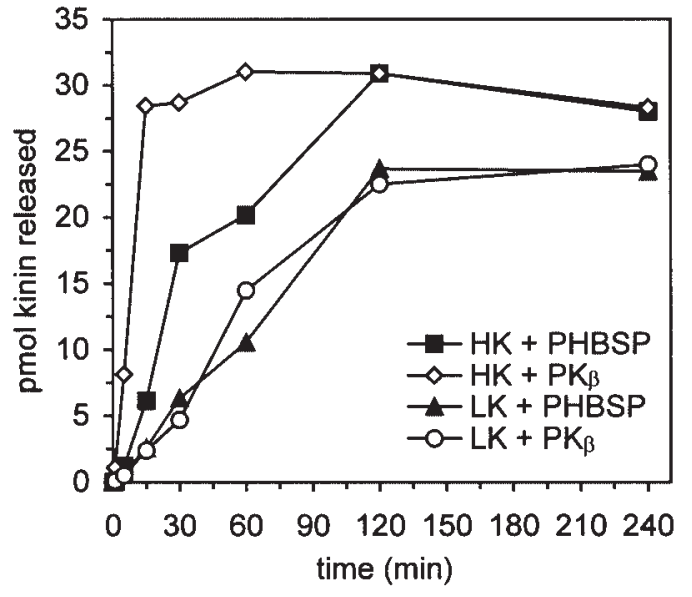

Fig. 4 Kinin Release.

The rate of kinin release from HMW kininogen $(\mathrm{HK})$ and LMW kininogen (LK) by PHBSP and PK $\beta$ was analyzed in a quantitative radioimmunoassay. The data for $\mathrm{HK}$ represent one of two independent experiments which yielded identical results. For comparison, kinin release from LK was once included. Each data point represents the average of two measurements.

kinin $(\sim 80 \%)$ within 60 min, a complete release of kinin was observed after $120 \mathrm{~min}$. PK completely released the kinin after 15 min already. The time course showed that with identical substrate to enzyme ratios $(35: 1)$ the release of kinin by PK occured at a much faster rate compared to PHBSP.

Low molecular weight kininogen (LK) showed repeatedly a slightly faster mobility upon treatment with PHBSP or $\mathrm{PK}_{\beta}$ in PAGE and immunoblot analysis (not shown). To further substantiate these observations, LK was included in the kinin release experiments. The results of the radioimmunoassay demonstrated that both, PHBSP and $\mathrm{PK}_{\beta}$ could process LK to release kinin. In contrast to HK, in the rate of kinin release from LK no significant difference between PK and PHBSP was detectable. The lack of the PK-binding $D 6_{\mathrm{H}}$ domain in LK did not prevent cleavage of LK by PK $\beta$. Only the rate and completeness of cleavage was affected. Whether the use of soley $\mathrm{PK}_{\alpha}$ compared to $\mathrm{PK}_{\beta}$ would result in a more pronounced difference in the rate of cleavage of HK and LK has not been determined during his study. In summary, the identical LK hydrolysis rate of both enzymes, PHBSP and PK $\beta$, further supports the assumption that they have very similar catalytic properties.

\section{Identity of the Kinin}

The results of the radioimmunoassay confirmed the release of kinin from HK or LK. However, whether it was the nonapeptide bradykinin, the decapeptide kallidin (Lys-bradykinin) or smaller BK-metabolites could not be clearly answered because the anti-BK antibody used for detection did not discriminate between these kinin forms. Using MALDI-TOF mass spectrometry, in the ethanol supernatant of PHBSP-treated HK a peak corresponding to 1060.69 was detected, confirming that 
bradykinin ( $\mathrm{NH}_{2}$-Arg-Pro-Pro-Gly-Phe-Ser-Pro-Phe-Arg$\mathrm{COOH} ; M_{\mathrm{r}}=1060.22$ ) was generated (Figure 5A). Another signal of 904.50 might represent desArg-BK. A peak of 1076.72 corresponds to the mass of BK with an additional hydroxyl group, most likely at the $\mathrm{C} 4$ of the proline located on the amino side of a glycine, yielding [Hyp $\left.{ }^{3}\right]-$ BK $\left(M_{r}=1076.2\right.$; Sasaguri et al., 1988). All the BK-related peaks were also observed when $\mathrm{PK} \beta$ was used as enzyme (Figure $5 \mathrm{~B}$ ), once more confirming the catalytic similarity betweeen PK and PHBSP. Two possibilities describe the origin of the desArg-BK peak. It could result from partial hydrolysis of the $\mathrm{Arg}_{263}-\mathrm{PrO}_{264}$ bond in $\mathrm{HK}$ instead of the $\mathrm{LyS}_{362}-\mathrm{Arg}_{363}$ bond in the second cleavage step of HK processing, thus liberating desArg1-BK. One hour treatment of synthetic bradykinin with PHBSP or $\mathrm{PK} \beta$, however, did not result in the removal of Arg1 from BK as determined by MALDI-TOF mass spectrometry (not shown). Another possibility would be that BK is partially metabolized by traces of kininase I (carboxypeptidase $\mathrm{N}$ ) removing the $\mathrm{C}$-terminal arginine residue and generating desArg9-BK (Murphey et al., 2000). As expected, the cleavage of LK by PHBSP or PK $\beta$ also resulted in the release of BK as determined by MALDI-TOF mass spetrometry (data not shown).

\section{Influence of GAGs on Kininogen Cleavage}

The affinity of PHBSP to hyaluronic acid and glycosoaminoglycans (GAGs) like heparin and the function of proteoglycans containing heparan sulfate or chondroitin sulfate (HS and CS) as cell surface receptors for HK (Renné et al., 2000; Renné and Müller-Esterl, 2001) raised the question whether kininogen cleavage may be promoted

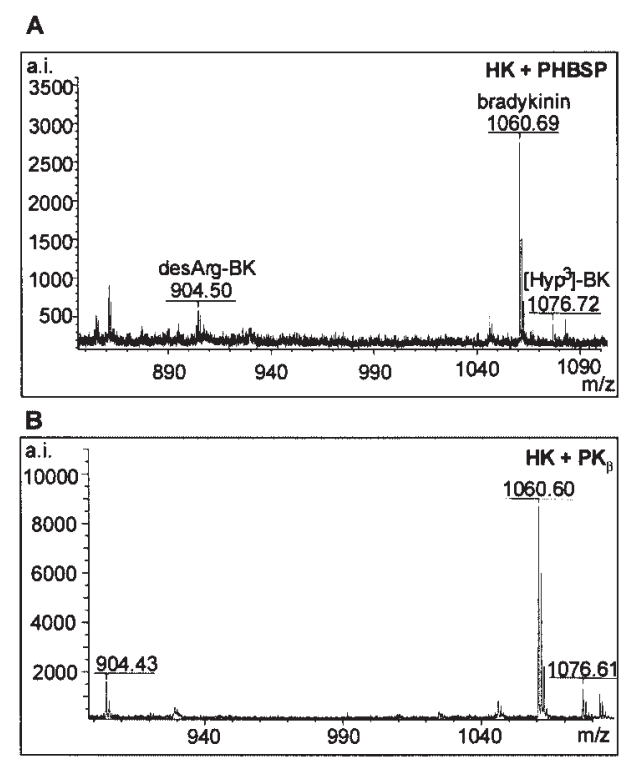

Fig. 5 MALDI-TOF Mass Spectrometric Analysis of Kinin Released from HMW Kininogen.

(A) Incubation of HK with PHBSP; (B) incubation with PK $\beta$. The masses of peaks corresponding to bradykinin $(\mathrm{BK})$ and related metabolites, desArg-BK and hydroxyproline-BK ([Hyp $\left.\left.{ }^{3}\right]-B K\right)$ are indicated.
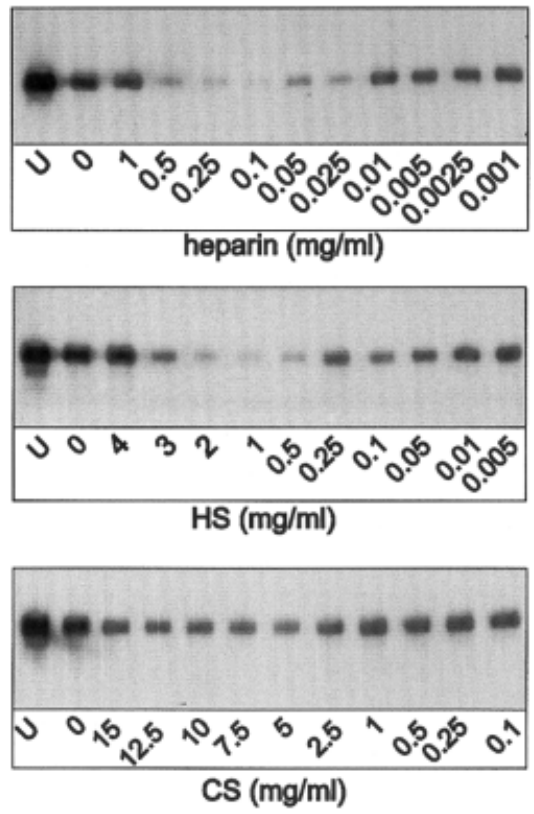

Fig. 6 Effect of Glycosoaminoglycans on Kininogen Activation. Cleavage of HK by PHBSP (ratio 35:1) was studied in the presence of increasing concentrations of the GAGs heparin, heparan sulfate (HS), and chondroitin sulfate (CS) as indicated. Cleavage proceeded for $10 \mathrm{~min}$ at room temperature and aliquots corresponding to $60 \mathrm{ng} \mathrm{HK}$ were subjected to PAGE and immunoblot analysis. Each gel is representitive of at least three independent experiments.
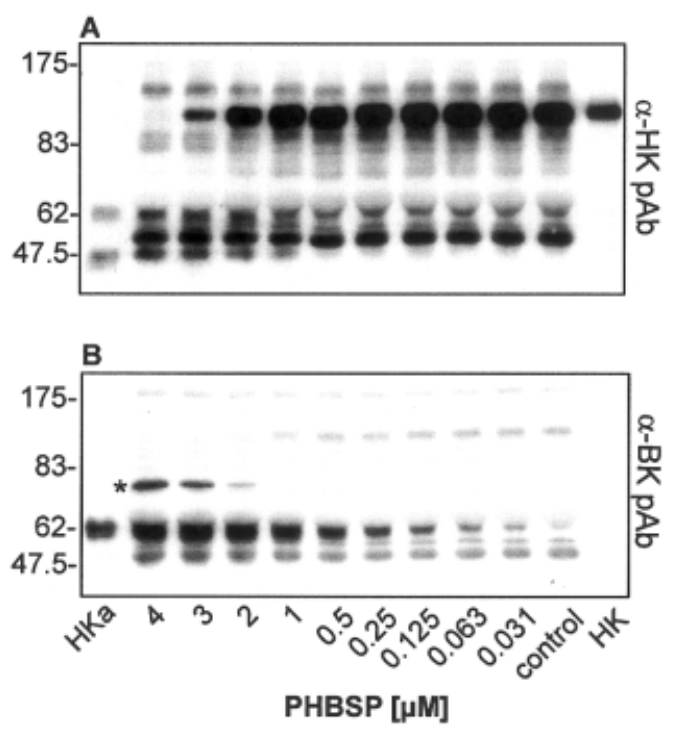

Fig. 7 Cleavage of HMW Kininogen in Human Plasma.

Ten $\mu \mathrm{l}$ freshly donated and citrated plasma was inubated for 90 min with one $\mu \mathrm{l}$ of PHBSP in a final concentration as indicated below each lane. The plasma samples were separated by SDSPAGE under reducing conditions and were transferred to a PVDF membrane. HK and the BK moiety were immunodetected with $(A)$ an anti-HK polyclonal antibody $(\alpha-H K ~ p A b)$, or (B) an anti-BK polyclonal antibody ( $\alpha-B K \mathrm{pAb})$. In the $120 \mathrm{kDa}$ pro-cofactor (HK) the BK moiety was not immunodetectable, but was detectable in cleaved kininogen (HKa). LMW kininogen (66 kDa) comigrated with serum albumin and was not detectable by immunoblot under the chosen conditions. 
by GAGs. When HK cleavage was studied as function of HS, CS or unfractionated heparin a concentration-dependent increase of kininogen cleavage was found by PAGE and Western blot (Figure 6). At $>1 \mathrm{mg} / \mathrm{ml} \mathrm{CS}$, $\sim 0.5-2 \mathrm{mg} / \mathrm{ml}$ HS or $0.025-0.25 \mathrm{mg} / \mathrm{ml}$ heparin $(\sim 5-47 \mathrm{IU} / \mathrm{ml})$ a maximum of $\mathrm{HK}$ cleavage was found, indicating that an optimum concentration of these charged molecules facilitate cleavage of HK by PHBSP. The effect of CS was less pronounced compared to HS or heparin. Interestingly, in an earlier study a maximum of autocatalytic activation of proPHBSP was found at a heparin concentration of 5-10 $\mathrm{IU} / \mathrm{ml}$ with an approximately 6fold increase in activation (Etscheid et al., 2000). This implicates that at a similar optimum concentration of charged GAGs like heparin two important physiologic processes would be promoted, autoactivation of the zymogen and cleavage of a natural substrate. Whether the in vitro effects of HS, CS and heparin are of biological importance, e.g. on the surface of endothelial or other cells, deserves further investigations.

\section{Cleavage of HK in Human Plasma}

The in vitro findings presented above indicated that $\mathrm{HK}$ is processed by PHBSP in solution to finally liberate bradykinin and activated cofactor, HKa. Consequently we addressed the question whether HK, circulating in plasma in complex with PK or FXI, could be a substrate for PHBSP. When citrated pool plasma was incubated for 90 min with increasing concentrations of purified PHBSP (31.25 nM-4 $\mu \mathrm{M})$, significant cleavage of HK could be observed only at rather high PHBSP concentrations of $2 \mu \mathrm{M}$ or above (Figure 7A). At $4 \mu \mathrm{M}$ PHBSP an almost complete processing of $\mathrm{HK}$ was detected. Using a BK-specific antibody (Figure 7B) it was observed that upon cleavage of $\mathrm{HK}$ a $62 \mathrm{kDa}$ band was generated, presumably the heavy chain with the $\mathrm{BK}$ moiety attached to its $\mathrm{C}$-terminus. This occured already at PHBSP concentrations below the plasma concentration of proPHBSP (200 nM). An additional BK-specific $\sim 75 \mathrm{kDa}$ band (asterisk in Figure 7B) was also found upon incubation of plasma with purified $\mathrm{PK} \beta$, the identity of this band is still unclear. Our data clearly demonstrate that PHBSP has the potency to cleave the contact phase procofactor HK present in plasma, albeit quantitatively only at elevated, non-physiologic concentrations and prolonged incubation. Whether LK, circulating in plasma at a concentration of $1.3 \mu \mathrm{M}$, is also cleaved by PHBSP has not been determined during this study.

Next, the cleavage of HK in plasma was studied time-
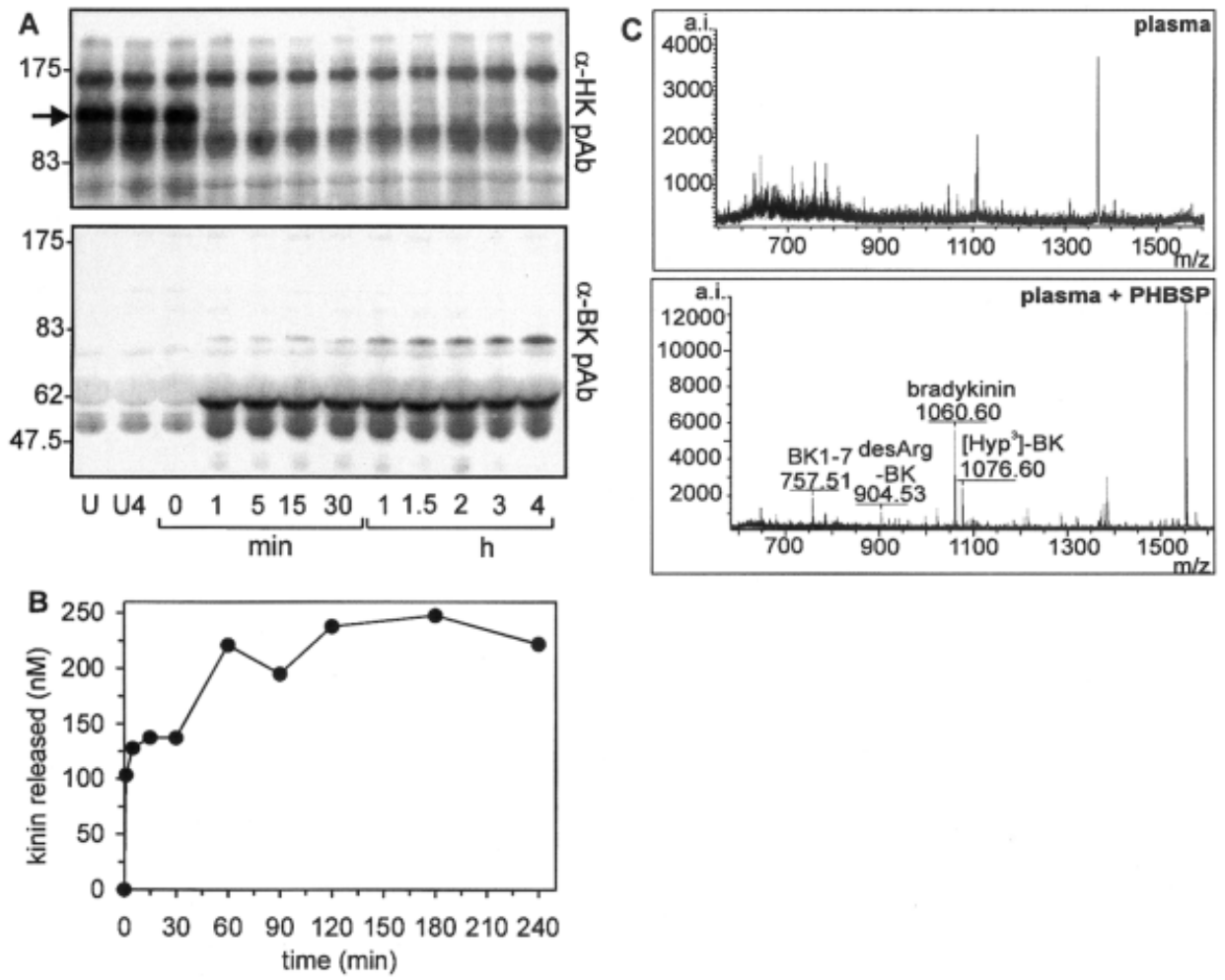

Fig. 8 Time Course of Kinin Release by PHBSP Activity in Plasma.

The cleavage of HK by $3 \mu \mathrm{M}$ PHBSP added to human plasma was analyzed by Western blotting with an anti-HK polyclonal antibody and with an anti-BK polyclonal antibody (A) as described in Figure 5. The time of incubation is indicated below each lane. The position of uncleaved HK is indicated by an arrow. (B) Radioimmunoassay of the time-course of kinin release. Each data point represents the average of two measurements. (C) Identity of the kinin. The supernatant of ethanol-precipitated human plasma that had been incubated for 90 min in the absence (top) or in the presence of $3 \mu \mathrm{M}$ PHBSP (bottom) was analyzed by MALDI-TOF mass spectrometry. Peaks corresponding to BK and BK metabolites are labeled. 
resolved at a fixed concentration of PHBSP (3 $\mu \mathrm{M})$. Soybean trypsin inhibitor and the ACE inhibitor captopril were present at $1 \mu \mathrm{M}$ and $10 \mathrm{~mm}$, respectively, to inhibit $\mathrm{PK}$ and to prevent metabolization of BK by angiotensin converting enzyme (ACE). Upon addition of PHBSP the procofactor band disappeared instantly concomitant with the generation of the $62 \mathrm{kDa} B K$ signal (Figure 8A) and free kinin (Figure 8B). A complete release of $\mathrm{BK}$ from the kininogen heavy chain was not observed. Under the chosen conditions PHBSP was able to release $100 \mathrm{~nm}$ kinin within the first min of incubation. At prolonged incubation, however, a total of $\sim 240 \mathrm{~nm}$ kinin were released. Based on the total concentration of HK + LK in plasma, $2 \mu \mathrm{M}$, PHBSP completely processed $>10 \%$ of plasma kininogens.

Finally we determined by MALDI-TOF mass spectrometry which BK metabolites could be found. Comparing plasma incubated for $60 \mathrm{~min}$ at RT in the absence or presence of PHBSP (Figure $8 \mathrm{C}$ ) showed clearly the generation of peaks corresponding to $\mathrm{BK}\left(M_{\mathrm{r}}=1060.60\right)$, des$\operatorname{Arg}-\mathrm{BK}\left(M_{\mathrm{r}}=904.53\right)$, [Hyp 3 -BK $\left(M_{\mathrm{r}}=1076.60\right)$ and a peak identical to $B K 1-7\left(M_{\mathrm{r}}=757.51\right)$ all of which were not visible in the PHBSP-free control. The generation of small BK metabolites BK1-7 and BK1-8 (desArg-BK) could be expected because in plasma BK has a rapid turnover with a half life of only $17 \mathrm{~s}$ (Murphey et al., 2000). In summary, our data unequivocally demonstrate that PHBSP cleaves HK (and presumably LK) in plasma and generates the vasoactive peptide bradykinin.

\section{Discussion}

The results of our study demonstrate that PHBSP has the potency to activate high and low molecular weight kininogen in vitro. The predominant products of cleavage of HK by PHBSP (Figure 9) are comparable to those generated by plasma kallikrein. Additionally we found that both, PHBSP and PK $\beta$, can use LK as substrate releasing $\mathrm{BK}$ and cleaved LK with the small light chain remaining attached to the heavy chain of LK by a disulfide bridge. Treatment of HK with PHBSP for prolonged time partially lead to further cleavage of the light chain in domain $\mathrm{D} 5_{\mathrm{H}}$, removing at least the first surface and cell binding region from HKa. Unlike PK and PHBSP, FXla inactivates the cofactor by removing both surface binding regions from the light chain, hence separating the $D 5_{H}$ from the $D 6_{H}$ domain and thus abolishing the procoagulatory function of HKa (Scott et al., 1985; Mauron et al., 2000). The removal of only the N-terminal part of the surface binding domain D5 ${ }_{H}$ by PHBSP might be involved in the regulation of $\mathrm{HK}$ functions at cell surfaces where interactions with peptides up to $\mathrm{Lys}_{480}$ are required, e.g. in proliferation and migration of endothelial cells (Colman et al., 2000) or in the binding of HK to neutrophils (Khan et al., 1998).

When PHBSP was added to human plasma an almost complete cleavage of HK was observed, including the dominant fraction of $\mathrm{HK}$ that circulates in plasma in com-
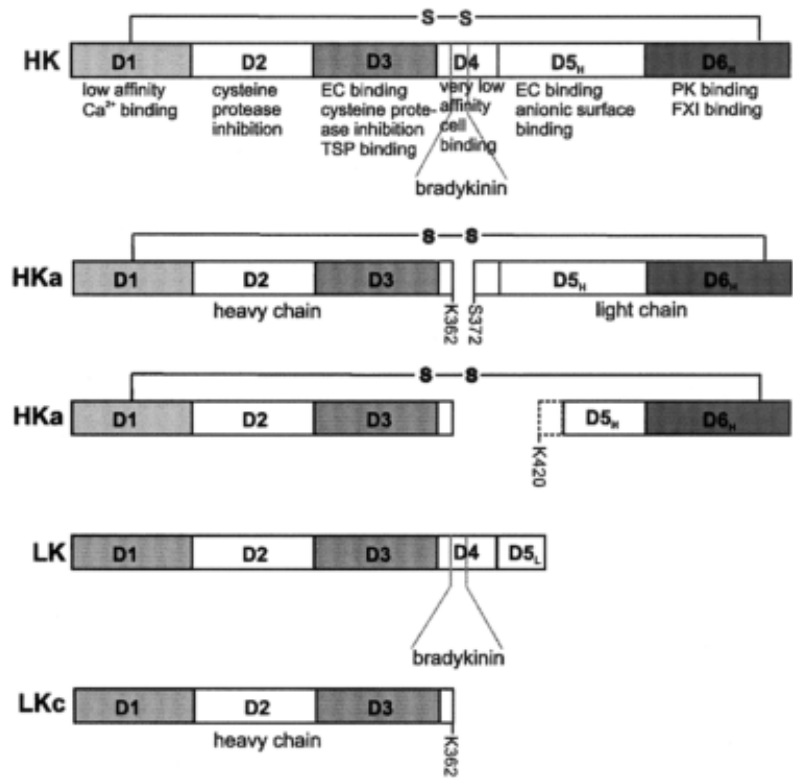

Fig. 9 Domain Structure and PHBSP Cleavage of Kininogens. The single-chain precursors HK and LK as well as the products generated by PHBSP are shown. HK and LK are transcribed from the same single copy gene as unique mRNAs by alternative splicing (Takagaki et al., 1985). The structure and characteristics of the domains are shown as described recently (Zhang et al., 2000; Colman, 2001). The termini generated by PHBSP are indicated. The fragment released from the $\mathrm{D}_{\mathrm{H}}$ domain of $\mathrm{HKa}$ by prolonged incubation with PHBSP is shown with dotted lines. Upon cleavage of LK (LKc) bradykinin is released, while the domain D5 remains attached to the heavy chain of LMW kininogen by a single disulfide bridge (Kellermann et al., 1987).

plex with prekallikrein or FXI. Apparently, prekallikrein and FXI bound to HK do not affect cleavage of HK by PHBSP. The data presented here suggest that cleavage of $\mathrm{HK}$ in plasma by physiological concentrations of $\mathrm{PHB}-$ $\mathrm{SP}($ proPHBSP $=200 \mathrm{~nm}$ ) is unlikely to release significant amounts of BK. At sites of increased (pro)enzyme and reduced inhibitor concentrations, however, e.g. at GAGs on cell surfaces or in the perivascular environment, the situation would presumably be different. The propensity of PHBSP to bind to GAGs like hyaluronic acid (Choi-Miura et al., 1996), the major component of the extracellular matrix (Laurent and Fraser, 1992) or to heparin, raises the possibility that autoactivation of the zymogen and kininogen cleavage with concomitant BK release could be directed to cell surfaces or to the extravascular environment. Although BK release by PHBSP in solution was less complete compared to $\mathrm{PK} \beta$, the amount of BK released would presumably be sufficient to produce a local effect, e.g. on cell surfaces. In plasma HK and LK are present at concentrations of $0.66 \mu \mathrm{M}$ and $1.3 \mu \mathrm{M}$, respectively, and $>100 \mathrm{~nm}$ free kinin were found within $1 \mathrm{~min}$ of incubation of plasma with PHBSP. Already 3 nм BK, however, can be sufficient to stimulate cellular responses (Busse and Lamontagne, 1991). Furthermore, cultured human umbilical vein endothelial cells (HUVECs) can ex- 
press HK on their surface at a concentration of approximately $9 \times 10^{3} \mathrm{HK}$ molecules/cell (Schmaier et al., 1988), and express $1 \times 10^{7} \mathrm{HK}$ binding sites/cell (Zhao et al., 2001), thus locally increasing the concentration of HK on cell surfaces. Two GAGs, heparan sulfate and chondroitin sulfate have been described as cell surface receptors of kininogen (Renné et al., 2000; Renné and Müller-Esterl, 2001), and in this study they promoted HK cleavage by PHBSP in vitro. Therefore a locally elevated concentration of HSPGs or CSPGs might promote HK activation by PHBSP.

The ability of PHBSP and PK to activate both, kininogens and prourokinase (sc-uPA) (Römisch et al., 2000), indicates that PHBSP has an overlapping substrate specificity with PK. Cleavage of FXII, which is a substrate of PK, was not observed for PHBSP. In contrast, activation of FVII and inactivation of FVIII or FV were found for PHBSP (Römisch et al., 1999) but not for PK, indicating that they do not share all enzymatic activities.

The heavy chain of PHBSP consists of three epidermal growth factor-like domains and one kringle domain, whereas the heavy chain of PK possesses four apple domains, three of which are involved in HK-binding (Page et al., 1994; Renné et al., 1999). Binding experiments showed that PHBSP has only a weak or no affinity to HK. In plasma proPHBSP most likely does not form stable complexes with HK, whereas PPK and FXI are found predominantly associated with HK (Mandle et al., 1976; Thompson et al., 1977). Through this interaction substrate and proenzyme are in close proximity, facilitating activation of the plasma kallikrein/kinin system, e.g. on endothelial cells (Rojkjaer and Schmaier, 1999). The structural differences in the heavy chain may direct the function of PK and PHBSP to different locations, where they exhibit similar activities.

It can be hypothesized that HK expressed on endothelial cells or bound to cell matrix (Colman et al., 1985) rather than $\mathrm{HK}$ circulating in blood in complex with PPK or FXI would be a substrate for PHBSP. BK liberated from bound $\mathrm{HK}$ could stimulate its endothelial cell receptor $\mathrm{B}_{2}$ to trigger subsequent intracellular reactions like the release of intracellular $\mathrm{Ca}^{2+}$ (Busse and Fleming, 1996). Indeed, recent studies demonstrated the PHBSP-mediated release of $\mathrm{Ca}^{2+}$ from endogeneous stores in cultured HUVECs, a process that was dependent on the proteolytic activity of PHBSP. Interaction with the protease-activated receptors PAR $1-4$ could be excluded during this study (Storck et al., 1999). Since HK and HK receptors are synthesized in cultured endothelial cells and are expressed on the cell surface (Schmaier et al., 1988) the PHBSP-dependent $\mathrm{Ca}^{2+}$ release in HUVECs might be attributed to the liberation of BK from cell- or matrix-bound HK. Further experiments are required to support this hypothesis.

While scuPA is autocatalytically inactive and does not cleave HK, it can be speculated that surface-bound proPHBSP autoactivates and promotes HK or sc-uPA activation and thus initiates subsequent reactions: (i) promoting the binding of HK to cell surface receptors. On endothelial cells HKa, but not HK can bind to domain 2 and 3 of the urokinase receptor (UPAR) in a zincdependent reaction. The generation of $\mathrm{HKa}$ and binding of HKa to UPAR (Colman et al., 1997) are initial steps in cell adhesion, proliferation and angiogenesis (Chavakis et al., 2000; Colman et al., 2000; Sheng et al., 2000).

(ii) Activation of surface-bound sc-uPA. This would result in plasmin generation on the cell surface, initiating cellassociated fibrinolysis.

The surface-bound plasminogen activator-plasmin system plays a pivotal role in the proteolytic cascade resulting in the activation of matrix metalloproteases, matrix degradation and tissue remodeling (Saksela and Rifkin, 1988; Mignatti and Rifkin, 1996). Further investigations are required to elucidate the in vivo importance of the HKand scuPA-activating potency of PHBSP in processes like fibrinolysis, angiogenesis, inflammation or blood pressure regulation.

\section{Materials and Methods}

\section{Proteins and Antisera}

PHBSP was prepared as described recently (Hunfeld et al., 1999). The goat polyclonal antibody to kininogen was obtained from ICN (Eschwege, Germany), the rabbit polyclonal antibradykinin antibody used in Western blots was from Affiland (Ans-Liege, Belgium), horseradish peroxidase-conjugated secondary antibodies were from Sigma (Deisenhofen, Germany). The kininogens and all proenzymes and enzymes were purchased from Calbiochem (Bad Soden, Germany) unless stated otherwise.

\section{Gel Electrophoresis and Western Blot Analysis}

Samples were separated by SDS-PAGE according to Laemmli (1970) and proteins were visualized by Coomassie Brilliant Blue staining of the gel. For Western blot analyses of HK processing, $100 \mathrm{ng} \mathrm{HK}$ were loaded to the gel and were transferred to a PVDF membrane (Millipore, Eschborn, Germany). HK and its processing products were visualized by immunodetection using a kininogen- or a bradykinin-specific antibody. After incubation with secondary antibodies the labeled proteins were detected with the chemiluminescent substrate ECL (Amersham-Pharmacia, Freiburg, Germany).

\section{Amino Acid Sequence Analysis}

After complete cleavage, $15 \mu \mathrm{g} \mathrm{HK}$ was equally distributed into 3 lanes of a $5-20 \%$ Laemmli gel and separated under reducing conditions. The protein was transferred to a PVDF membrane and the protein bands were visualized by Coomassie Brilliant Blue staining. The $\mathrm{N}$-terminal amino acid sequence was determined by Edman degradation on an Applied Biosystems Procise Sequencer as described earlier (Hunfeld et al., 1999).

\section{Cleavage Reactions}

HMW and LMW kininogen (2.7 $\mu \mathrm{M}$ each), respectively, were incubated at room temperature with $78 \mathrm{~nm}$ of enzyme in cleavage buffer (50 mM Tris- $\mathrm{HCl}, 150 \mathrm{~mm}$ sodium chloride, $10 \mathrm{~mm}$ calci- 
um chloride and $0.1 \%$ Tween $20, \mathrm{pH} 7.8$ ). For gel analysis identical volumes were withdrawn at the specified time points and were immediately added to $1 / 3$ vol gel loading buffer ( $1 \%$ SDS, $2 \%$ mercaptoethanol, $0.02 \%$ bromophenol, $10 \%$ glycerol) and boiled for 5 minutes. Samples were subjected to SDS-PAGE and Western blot analysis. The cleavage of HK was also studied as function of the GAGs heparan sulfate, chondroitin sulfate, and heparin at identical enzyme to substrate ratio as described above. The reaction proceeded for $10 \mathrm{~min}$ at room temperature. The reaction was stopped by adding $1 / 3$ vol. gel loading buffer, and $60 \mathrm{ng}$ HK was subjected to PAGE and immunoblot analysis.

\section{Radioimmunoassay}

Incubation of HK or LK with PHBSP or PK $\beta$ was performed as described above. At each time point $10 \mu \mathrm{l}$ (corresponding to $27 \mathrm{pmol} \mathrm{HK}$ ) were withdrawn and added to $40 \mu \mathrm{l}$ of a stop solution (50 mM Tris- $\mathrm{HCl}, 150 \mathrm{~mm} \mathrm{NaCl}, 40 \mathrm{~mm}$ EDTA, $4 \mathrm{~mm}$ orthophenanthroline, $\mathrm{pH}$ 7.8). Immediately, this solution was added to $950 \mu \mathrm{l} 96 \%$ ethanol, incubated at $70^{\circ} \mathrm{C}$ for $10 \mathrm{~min}$, followed by rapid cooling on ice and sedimentation for $5 \mathrm{~min}$ at $12000 \mathrm{~g}$ at $4^{\circ} \mathrm{C}$ in a Heraeus Biofuge (Hanau, Germany). The pellet was reextracted with $96 \%$ ethanol and treated as above, and the combined supernatants were evaporated in a speed vac (Eppendorf, Hamburg, Germany). The amount of kinin present in the supernatant was determined by radioimmunoassay as described in Fink et al. (1985).

\section{Mass Spectrometric Analysis}

The kinin-containing fraction of the samples was obtained as described above. The masses of peptides in the evaporated supernatant were determined by matrix-assisted laser desorption/ionization-time of flight (MALDI-TOF) mass spectrometry in a 3,5-dimethoxy-4-hydroxycinnamic acid matrix on a BIFLEX III system (Bruker Saxonia Analytik, Leipzig, Germany) using the reflection mode. The mass $(\mathrm{m} / \mathrm{z}$ ratio) of each fragment was calculated by comparing the experimental data to molecular weight standards that were used for calibration as recommended by the manufacturer.

\section{HK Binding Assays}

The wells of a 96 well microtiter plate (Maxisorb; Nunc, Wiesbaden, Germany) were coated overnight at $4^{\circ} \mathrm{C}$ with $100 \mu$ of $10 \mu \mathrm{g} / \mathrm{ml} \mathrm{HK}$ in coating buffer ( $35 \mathrm{~mm} \mathrm{NaHCO}_{3}, 15 \mathrm{~mm} \mathrm{NaCl}$, pH 9.6), blocked with $2 \% \mathrm{BSA}$ overnight at $4{ }^{\circ} \mathrm{C}$, and incubated for $1 \mathrm{~h}$ at $37^{\circ} \mathrm{C}$ with $100 \mu \mathrm{l}$ of a geometrical dilution series of the protein of interest $(1-0,156 \mu \mathrm{g} / \mathrm{ml})$. After washing 4 times with HBS $+0.1 \%$ Triton X-100 the bound ligands were fixed by incubation with $2 \%$ formaldehyde for 20 min at room temperature and were detected by subsequent addition of anti-PHBSP or anti-PK primary and POD-labeled secondary antibodies. The development of the substrate 3,3',5,5'-tetramethylbenzidine (Sigma, Deisenhofen) proceeded for $30 \mathrm{~min}$ and the absorption at $450 \mathrm{~nm}$ was determined in an ELISA reader (SLT, Offenburg, Germany).

\section{Cleavage of Kininogen in Human Plasma}

Undiluted citrated pool plasma was incubated for $90 \mathrm{~min}$ at room temperature with $1 / 10$ vol of a dilution series of PHBSP (final concentration: $4 \mu \mathrm{M}-31.25 \mathrm{nM}$ ). The reaction was stopped by adding $90 \mu \mathrm{l}$ of gel loading buffer including B-mercaptoethanol and boiling for 10 minutes. Samples were loaded on a 5-20\% gel for SDS-PAGE. After protein transfer to a PVDF membrane, $\mathrm{HK}$ or BK were visualized by immunodetection. Additionally, the identity of the free kinin was determined by MALDI-TOF mass spectrometry.

Alternatively, in a time course experiment plasma was treated with $3 \mu \mathrm{M}$ PHBSP in the presence of $1 \mu \mathrm{M}$ soybean trypsin inhibitor (Roche Pharmaceuticals, Mannheim, Germany) to supress potential PK activity and $10 \mathrm{~mm}$ captopril (Sigma) to prevent bradykinin metabolisation by angiotensin converting enzyme (ACE). At various time points (0-240 min) samples were withdrawn and analysed by western analysis, radioimmunoassay, and MALDI-TOF mass spectrometry as described above.

\section{Acknowledgements}

We are very grateful to Prof. K. Shimamoto, Sapporo, Japan, for providing the anti-bradykinin antibody used in the radioimmunoassays. The assistence of Dr. W. Schilow and E. SchörnerBurkhardt in mass spectrometry analysis is highly acknowledged. This work was supported by the Federal Ministry of Health.

\section{References}

Baglia, F.A., Jameson, B.A., and Walsh, P.N. (1990). Localization of the high molecular weight kininogen binding site in the heavy chain of human factor XI to amino acids phenylalanine 56 through serine 86. J. Biol. Chem. 265, 4149-4154.

Busse, R. and Fleming, I. (1996). Molecular responses of endothelial tissue to kinins. Diabetes 45, S8-S13.

Busse, R. and Lamontagne, D. (1991). Endothelium-derived bradykinin is responsible for the increase in calcium produced by angiotensin-converting enzyme inhibitors in human endothelial cells. Naunyn-Schmiedebergs Arch. Pharmacol. 344, $126-129$.

Cameron, C.L., Fisslthaler, B., Sherman, A., Reddigari, S., and Silverberg, M. (1989). Studies on contact activation: effects of surface and inhibitors. Med. Prog. Technol. 15, 53-62.

Chavakis, T., Kanse, S.M., Lupu, F., Hammes, H.-P., Müller-Esterl, W., Pixley, R.A., Colman, R.W., and Preissner, K.T. (2000). Different mechanisms define the antiadhesive function of high molecular weight kininogen in integrin- and urokinase receptor-dependent interactions. Blood 96, 514-522.

Choi-Miura, N.H., Tobe, T., Sumiya, J., Nakano, Y., Sano, Y., Mazda, T., and Tomita, M. (1996). Purification and characterization of a novel hyaluronan-binding protein (PHBP) from human plasma: it has three EGF, a kringle and a serine protease domain, similar to hepatocyte growth factor activator. J. Biochem. 119, 1157-1165.

Choi-Miura, N.H., Saito, K., Takahashi, K., Yoda, M., and Tomita, M. (2001). Regulation mechanism of the serine protease activity of plasma hyaluronan binding protein. Biol. Pharm. Bull. 24, 221-225.

Cochrane, C., and Griffin, J.H. (1979). Molecular assembly in the contact phase of the Hageman factor system. Am. J. Med. 67, 657-664.

Colman, R.W. (2001). Contact activation pathway: Inflammatory, fibrinolytic, anticoagulant, antiadhesive, and antiangiogenic activities. In: Hemostasis and Thrombosis, Basic Principles and Clinical Practise, R.W. Colman, J. Hirsh, V.J. Marder, A.W. Clowes and J.N. George, eds. (Philadelphia, USA: Lippincott Williams \& Wilkins), pp. 103-121.

Colman, R.W. and Schmaier, A.H. (1997). Contact system: a vascular biology modulator with anticoagulant, profibrinolytic, antiadhesive, and proinflammatory attributes. Blood 90, $3819-3843$. 
Colman, R.W., Pixley, R.A., Najamunnissa, S., Yan, W., Wang, J., Mazar, A., and McCrae, K.R. (1997). Binding of high molecular weight kininogen to human endothelial cells is mediated via a site within domains 2 and 3 of the urokinase receptor. J. Clin. Invest. 100, 1481-1487.

Colman, R.W., Bradford, A.J., Lin, Y., Johnson, D., and Mousa, S.A. (2000). Domain 5 of high molecular weight kininogen (kininostatin) down-regulates endothelial cell proliferation and migration and inhibits angiogenesis. Blood 95, 543-550.

De La Cadena, R.A., Wachtfogel, Y.T., and Colman, R.W. (1994). Contact activation pathway: inflammation and coagulation. In: Hemostasis and Thrombosis: Basic Principles and Clinical Practice, R.W. Colman, J. Hirsh, V.J. Marder, and E.W. Salzman, eds. (Philadelphia, USA: Lippincott Co.), pp. 219-228.

Donaldson, V.H, Glueck, H.I., Miller, M.A., Movat, H.Z., and Habal, F. (1976). Kininogen deficiency in Fitzgerald trait: role of high molecular weight kininogen in clotting and fibrinolysis. J. Lab. Clin. Med. 87, 327-337.

Etscheid, M., Hunfeld, A., König, H., Seitz, R., and Dodt, J. (2000). Activation of proPHBSP, the zymogen of a plasma hyaluronan binding serine protease, by an intermolecular autocatalytical mechanism. Biol. Chem. 381, 1223-1231.

Fink, E., Schill, W.-B., Fiedler, F., Krassnigg, F., Geiger, R., and Shimamoto, K. (1985). Tissue kallikrein of human seminal plasma is secreted by the prostate gland. Biol. Chem. HoppeSeyler 366, 917-924.

Hunfeld, A., Etscheid, M., König, H., Seitz, R., and Dodt, J. (1999). Detection of a novel plasma serine protease during purification of vitamin $\mathrm{K}$-dependent coagulation factors. FEBS Lett. 456, 290-294.

Kaplan, A.P. (1979). The role of high molecular weight kininogen in contact activation of coagulation, fibrinolysis and kinin generation. Adv. Exp. Med. Biol. 120, 71-91.

Kellermann, J., Thelen, C., Lottspeich, F., Henschen, A., Vogel, R., and Müller-Esterl, W. (1987). Arrangement of the disulphide bridges in human low- $M_{\mathrm{r}}$ kininogen. Biochem. J. 247, $15-21$.

Khan, A.R. and James, M.N.G. (1998). Molecular mechanisms for the conversion of zymogens to active proteolytic enzymes. Protein Sci. 7, 815-836.

Khan, M.M., Kunapuli, S.P., Lin, Y., Majluf-Cruz, A., Cadena, R.A., Cooper, S.L., and Colman, R.W. (1998). Three noncontiguous peptides comprise binding sites on high-molecularweight kininogen to neutrophils. Amer. J. Physiol. 275, H145H150.

Laemmli, U.K. (1970). Cleavage of structural proteins during the assembly of the head of the bacteriophage T4. Nature 227, $680-685$.

Laurent, T.C., and Fraser, J.R.E. (1992). Hyaluronan. FASEB J. 6 , 2397-2404.

Mandle, R.J., Colman, R.W., and Kaplan, A.P. (1976). Identification of prekallikrein and high-molecular-weight kininogen as a complex in human plasma. Proc. Natl. Acad. Sci. USA 73, 4179-4183.

Mauron, T., Lämmle, B., and Wuillemin, W.A. (2000). High molecular weight kininogen is cleaved by FXla at three sites: Arg409-Arg410, Lys502-Thr503 and Lys325-Lys326. Thromb. Haemost. 83, 709-714.

Mignatti, P., and Rifkin, D.B. (1996). Plasminogen activators and matrix metalloproteases in angiogenesis. Enzyme Protein 49, $117-137$.

Motta, G., Shariat-Madar, Z., Mahdi, F., Sampaio, C.A.M., and Schmaier, A.H. (2001). Assembly of high molecular weight kininogen and activation of prekallikrein on cell matrix. Thromb. Haemost. 86, 840-847.
Murphey, L.J., Hachey, D.L., Oates, J.A., Morrow, J.D., and Brown, N.J. (2000). Metabolism of bradykinin in vivo in humans: identification of BK1-5 as a stable plasma peptide metabolite. J. Pharmacol. Exp. Ther. 294, 263-269.

Page, J.D., You, J.L., Harris, R.B., and Colman, R.W. (1994). Localization of the binding site on plasma kallikrein for high molecular weight kininogen to both apple 1 and apple 4 domains of the heavy chain. Arch. Biochem. Biophys. 314, 159-164.

Renné, T., and Müller-Esterl, W. (2001). Cell surface-associated chondroitin sulfate proteoglycans bind contact phase factor H-kininogen. FEBS Lett. 500, 36-40.

Renné, T., Dedio, J., David, G., and Müller-Esterl, W. (2000). High molecular weight kininogen utilizes heparan sulfate proteoglycans for accumulation on endothelial cells. J. Biol. Chem. 275, $33688-33696$.

Renné, T., Dedio, J., Meijers, J.C., Chung, D., and Müller-Esterl, W. (1999). Mapping of the discontinuous H-kininogen binding site of plasma prekallikrein. Evidence for a critical role of apple domain-2. J. Biol. Chem. 274, 25777-25784.

Renné, T., Gailani, D., Meijers, J.C., and Müller-Esterl, W. (2002). Characterization of the $\mathrm{H}$-kininogen-binding site on factor $\mathrm{XI}$ : a comparison of factor $\mathrm{XI}$ and plasma prekallikrein. J. Biol. Chem. 277, 4892-4899.

Rojkjaer, R., and Schmaier, A.H. (1999). Activation of the plasma kallikrein/kinin system on endothelial cells. Proc. Assoc. Am. Phys. 111, 220-227.

Römisch, J., Feußner, A., Vermöhlen, S., and Stöhr, H.-A. (1999). A protease isolated from human plasma activating factor VII independent of tissue factor. Blood Coagul. Fibrinolysis 10, $471-479$

Römisch, J., Vermöhlen, S., Feußner, A., and Stöhr, H.-A. (2000). The FVII activating protease cleaves single-chain plasminogen activators. Haemostasis 29, 292-299.

Römisch, J., Feußner, A., and Stöhr, H.-A. (2001). Quantification of the factor VII-and single chain plasminogen activator-activating protease in plasmas of healthy subjects. Blood Coagul. Fibrinolysis 12, 375-383.

Saksela, O. and Rifkin, D.B. (1988). Cell-associated plasminogen activation: regulation and physiological functions. Annu. Rev. Cell Biol. 4, 93-126.

Sasaguri, M., Ikeda, M., Ideishi, M., and Arakawa, K. (1988). Identification of (hydroxyproline3)-bradykinin released from human plasma and plasma protein Cohn's fraction IV- 4 by trypsin. Biochem. Biophys. Res. Commun. 157, 210-217.

Schmaier, A.H. (2000). Plasma kallikrein/kinin system: a revised hypothesis for its activation and its physiologic contributions. Curr. Opin. Hematol. 7, 261-265.

Schmaier, A.H., Kuo, A., Lundberg, D., Murray, S., and Cines, D.B. (1988). Expression of high molecular weight kininogen on human umbelical vein endothelial cells. J. Biol. Chem. 263, 16327.

Scott, C.F., Silver, L.D., Purdon, A.D., and Colman, R.W. (1985). Cleavage of human high molecular weight kininogen by factor Xla in vitro. J. Biol. Chem. 260, 10856-10863.

Sheng, N., Fairbanks, M.B., Heinrikson, R.L.C.G., Chaiken, I.M., Mosser, D.M., Zhang, H., and Colman, R.W. (2000). Cleaved high molecular weight kininogen binds directly to the integrin CD11b/CD18 (Mac-1) and blocks adhesion to fibrinogen and ICAM-1. Blood 95, 3788-3795.

Storck, J., Hunfeld, A., and Dodt, J. (1999). A new human plasma serine protease activates endothelial cells. Pflüger's Arch. Eur. J. Physiol. 437 [5 (Suppl.)], R164.

Takagaki, Y., Kitamura, N., and Nakanishi, S. (1985). Cloning and sequence analysis of cDNAs for human high molecular weight and low molecular weight prekininogens. J. Biol. Chem. 260, 8609. 
Thompson, R.E., Mandle, R.J., and Kaplan, A.P. (1977). Association of factor $\mathrm{XI}$ and high molecular weight kininogen in human plasma. J. Clin. Invest. 60, 1376-1380.

Wiggins, R.C. (1983). Kinin release from high molecular weight kininogen by the action of Hageman factor in the absence of kallikrein. J. Biol. Chem. 258, 8963-8970.

Zhang, J.C., Claffey, K., Sakthivel, R., Darzynkiewicz, Z., Shaw, D.E., Leal, J., Wang, Y.-C., Lu, F.-M., and McCrae, K.R. (2000). Two chain high molecular weight kininogen induces endothe- lial cell apoptosis and inhibits angiogenesis: partial activity within domain 5. FASEB J. 14, 2589-2600.

Zhao, Y., Qiu, Q., Mahdi, F., Shariat-Madar, Z., Rojkjaer, R., and Schmaier, A.H. (2001). Assembly and activation of HK-PK complex on endothelial cells results in bradykinin liberation and NO formation. Am. J. Physiol. Heart Circ. Physiol. 280, $\mathrm{H} 1821-\mathrm{H} 1829$.

Received December 20, 2001; accepted April 18, 2002 